\title{
Impact of DFIG Based Wind Generation on Grid Voltage and Frequency Support
}

\author{
Md Aktarujjaman, Member, IEEE, M. E. Haque, Senior Member, IEEE, S. Saha and M. Negnevitsky, \\ Senior Member, IEEE
}

\begin{abstract}
Recent trends indicate replacement of fossil fuel driven conventional synchronous generators from the existing power grid with inverter interfaced renewable energy sources in coming years. A significant portion of these renewable energy sources is predicted to include doubly fed induction generator (DFIG) based wind turbine. This will cause a significant change in the grid dynamics, due to reduced system inertia and the intermittent nature of wind power. The impact of grid integration of DFIG-bases wind turbines on the grid voltage and frequency has been presented in this paper through rigorous simulation studies carried out using the professional simulation software PSS/E. The simulation studies are carried out on a power grid network model that includes hydro, gas and wind generation under different voltage and frequency contingencies or disturbances. Models of commercially available DFIG-based variable speed wind turbines from top manufacturers have been used in the simulation studies. The effect of inertia, loss of generations and loads on the system frequency, as well as the impact of different faults on system voltage are investigated and thoroughly analyzed. Furthermore, this study also includes the assessments of grid code requirements under for high penetration of DFIG based wind turbines in the power grid. Critical analysis of the simulation studies reveal that DFIG-based wind turbines are capable to contribute to system frequency and voltage regulation under different contingencies or network disturbances.

Index Terms - wind power generation, grid impact, frequency control, voltage regulation, inertial response.
\end{abstract}

\section{INTRODUCTION}

$\mathrm{W}$ ith the increasing penetration of wind energy sources in the power grid, it is necessary for the wind farms to provide grid support while they are connected to the power grid. Otherwise, it will be difficult for the grid operator to provide the required ancillary services and to maintain the required level of stability, reliability and security of the power grid [1],[2]. Currently, many countries have mandatory grid codes that imposes the wind farms to have the ancillary capabilities such as voltage support, frequency support, reactive power support and fault ride through capability [1], [3]. Among different types of wind turbines, the variable speed wind turbines have gained more popularity than the fixed speed wind turbines, because of their superior performance and several advantages such as improved dynamic behavior, increased energy capture, reduced mechanical stress and acoustic noise, improved lower quality and system efficiency. Moreover, operation at the maximum power point can be realized over a wide power range as the turbine speed can be adjusted with the variation of wind speed [4], [5]. The power electronic interfaces used in a variable speed wind turbine decouple it from the grid, and as a consequence, there will be a reduction in system inertia. A lower system inertial will result in larger and faster deviations in frequency after occurrence of abrupt variations in generation and system load [2], [6]. To ensure, power system stability and security, it is imperative to regulate the grid frequency at every instances. Traditionally, the grid frequency is regulated by the conventional fossil fuel power plants with synchronous generators. The larger inertia of the synchronous generators will cause a slower change in the rotor speed during power mismatch between the generation and load.
The current power system with synchronous generators has a relatively larger inertia, which contribute to stabilize the system under any disturbances.

However, the portfolios of power generation are changing and the dynamic behaviours of new power sources differ from the traditional one. With the recent advancement in power electronics and variable speed wind turbine technologies, it is anticipated that wind energy will supply the majority of future renewable energy generation target in many countries [7]. The differing dynamic performance and inertial response of variable speed wind turbines compared to conventional synchronous generators have caused concerns to power system engineers and grid operators. Moreover, with the increasing penetration of wind energy sources using variable speed technology, the grid frequency regulation is becoming difficult because of the low or no inertia of the converter fed wind turbines. However, it has been shown that with an additional control loop the variable speed wind turbine may be configured to emulate an inertial response similar to that of synchronous generation and can be used to regulate frequency [6], [8]-[10]. Also, as the penetration level is increasing it is necessary to let the variable speed wind turbines contribute to the system inertia and frequency regulation [9]

This paper presents a detail study and critical analysis on the impacts of large scale integration of different types of commercially available DFIG based variable speed wind turbines on the grid voltage and frequency. This study has been rigorously carried out using professional simulation software PSS/E on a real power system network including conventional hydro and gas power plants with synchronous generators, as well as DFIG based variable speed wind turbine. In the simulation studies, models of commercially available DFIG based variable speed wind turbines from top manufacturers are investigated to analyze the effect of reduction in inertia due to large scale integration of DFIG based variable speed wind turbines on grid voltage and frequency under different contingencies/events such as loss of generations and loads on system frequency, different faults have been thoroughly investigated. Furthermore, this study also include the assessments of grid code requirements under high penetration of DFIG based variable speed wind turbines in conventional power grid. The analysis of the simulation studies conclude that under different contingencies/events the DFIG-based wind turbines can provide ancillary services by contributing to the grid frequency and voltage regulation under different contingencies and grid disturbances.

\section{OVERVIEW OF DFIG BASED WIND TURBINE}

A typical DFIG based wind turbine generator system is shown in Fig.1. The generator uses a wound-rotor induction machine where the rotor terminals are fed via a back-to-back PWM voltage source converter rated at approximately $30 \%$ of the wind turbine system. The rotor side converter is responsible for controlling the speed of the generator and reactive power output, while the stator side converter controls the real power supply to the grid and may also be used to supply reactive power. The following equation describes 
the extracted mechanical $P_{m}$ by a wind turbine at a given wind speed $v_{\omega}$ air density $\rho$ and pitch angle $\beta[10]$.

$$
P_{m}=0.5 \rho A v_{\omega}^{3} C_{p}(\lambda, \beta)
$$

In (1) $C_{p}$ represents power coefficient of the wind turbine and is the tip speed ratio (TSR). If $\lambda$ is maintained at optimum value $\lambda^{*}$ the power coefficient $C_{p}$ is optimum and the wind generator extracts maximum mechanical power [11]. The relationship of $\lambda^{*}$ with the optimum turbine speed $\left(\omega_{m}\right)$ for a wind turbine with radius $R$ at wind speed $v_{\omega}$ is given by:

$$
\lambda^{*}=\frac{\omega_{m}^{*} R}{v_{\omega}} .
$$

The mechanical drive train of DFIG is commonly approximated by two mass model in per unit, as shown in (3), where $\omega_{t}, \omega_{g}$ and $\omega_{b}$ are turbine, generator and base angular speeds, respectively; $H_{t}$ and $H_{g}$ are turbine and generator inertia, respectively; $\theta_{t}$ is the angular displacement of the shaft; $T_{t}$ and $T_{g}$ are turbine and generator torque, respectively; $d_{m}$ is the mutual damping and $k$ represents the shaft stiffness.

$$
\begin{aligned}
\dot{\omega}_{t} & =\frac{\omega_{b}}{2 H_{t}}\left(T_{t}-d_{m}\left(\omega_{t}-\omega_{g}\right)-k \theta_{t}\right) \\
\dot{\omega}_{g} & =\frac{\omega_{b}}{2 H_{g}}\left(d_{m}\left(\omega_{t}-\omega_{g}\right)+k \theta_{t}-T_{g}\right)
\end{aligned}
$$

The stator and rotor side converters are commonly controlled using vector control approach to regulate the real and reactive power output of the DFIG based wind turbine [9], [10]. The DFIG based wind turbine can participate in primary frequency control of the interconnected grid, alongside other energy sources in the grid following the droop line shown in Fig. 2, which represents participation of a wind turbine in grid primary frequency control [9]. The dynamics of a wind turbine while participating grid frequency control can be expressed as

$$
J \frac{d \omega_{w t}}{d t}=T_{a}-T_{e}
$$

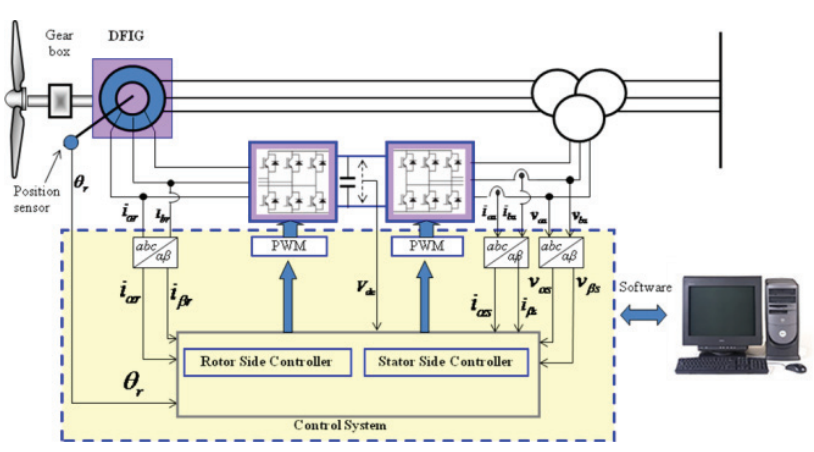

Fig.1 DFIG based wind turbine system.

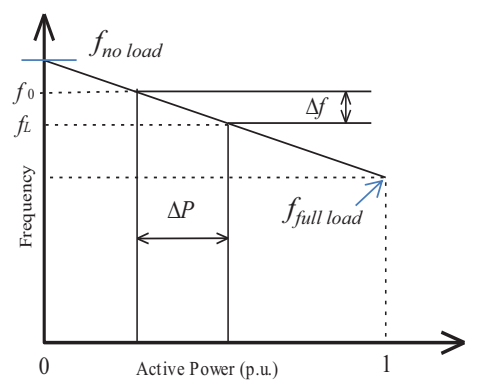

Fig.2. Typical frequency- power characteristic where $J=$ inertia of the rotor, $\omega_{w t}=$ rotational speed, $T_{e}=$ electromagnetic torque, and $T_{a}=$ aerodynamic torque which depends on the wind speed, pitch angle, and tip speed ratio.

The stored kinetic energy in the rotating mass of wind turbine is given by

$$
E=\frac{1}{2} J \omega_{w t}^{2}
$$

The inertia constant, $H$ which is used to quantify kinetic energy in the rotating mass of wind turbine is given by [11]

$$
H=\frac{E}{S_{n}}=\frac{J \omega_{w t}^{2}}{2 S_{n}}
$$

where $S_{n}=$ rated apparent power (MVA). Fig.3 shows the simplified dynamic model of DFG based variable speed wind turbine.

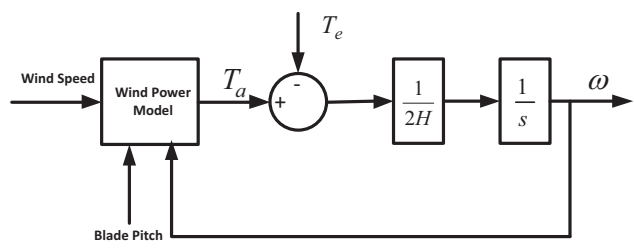

Fig.3. Simplified mechanical dynamic model for DFIG based wind turbine

\section{STUdIED System AND MODELING}

Fig. 4 shows the simulation setup for the wind farm for power flow studies. This simplified set-up shows a $100 \mathrm{MW}$ wind farm, which consists of several wind turbines, generation side step-up transformer, transmission line model, grid side power transformer and grid. Table I shows the required parameters for connecting different wind turbine into the network. A complete model used for power flow studies using PSSE is shown in Fig.5. The grid, hydro 1 and 2, Gas and wind farm are represented as synchronous generator for load flow studies. The wind farm with inertia is represented as a wind generator. The generator data for the studied system are given in Table II.

The total capacity of the wind farm is 112 MVA. The reactive power capability of the wind farm is according to Table I. The wind farm is connected to the collector bus 102 through $0.69 / 33$ $\mathrm{kV}$ transformer. A second step up transformer $(33 / 220 \mathrm{kV})$ is connected to collector bus 102 to the bus WF TERM 101. The rating of the transformer is $125 \mathrm{MVA}$. The source impedance of the wind generator and transformer are given Table I for load flow and dynamic simulations. Bus-100 is considered as a wind connection point for the network.

\section{REsults AND Discussions}

To study the impact of wind farm on the power grid two types of disturbances are investigated. These are frequency and voltage disturbances. Table III shows the fault information.

A. Frequency Disturbances: Two frequency disturbances are applied in the study system to assess the system frequency contribution by the wind farm.

Frequency disturbance 1 (FD1): A fault is introduced by tripping Hydro 1 machine connected to Bus 141. The system instantly losses $75 \mathrm{MW}$ generation due to the fault at Bus 141. Fig. 6 shows FD1 responses of voltage at PCC $\left(V_{-} C P\right)$, terminal voltage $\left(E_{t}\right)$, generated power $\left(P_{e}\right)$, frequency, terminal current $\left(I_{t}\right)$ and reactive power $(Q)$, for different wind turbine models. FD1 responses for wind turbines without inertia are also presented in Fig. 8. The largest frequency drops to $49.1 \mathrm{~Hz}$ for wind turbine without inertia whereas and the least frequency drop occurs for GE to $49.55 \mathrm{~Hz}$. 


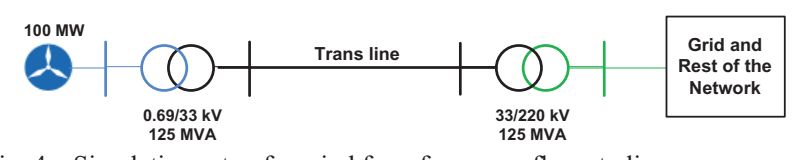

Fig. 4. Simulation setup for wind farm for power flow studies.

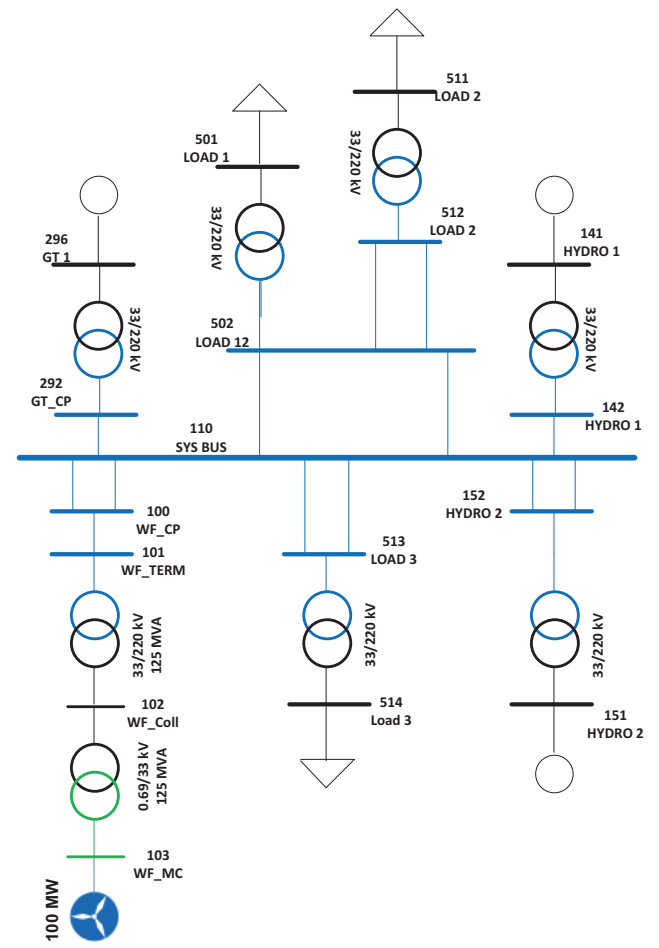

Fig.5. Studied system in PSSE.

TABLE I: PARMETERS FOR POWER FLOW SETUP

\begin{tabular}{|l|c|c|c|c|}
\hline \multicolumn{1}{|c|}{ Parameters } & Acciona & GE & Generic & Furhlander \\
\hline Pmax (MW) & 100 & 100 & 100 & 100 \\
\hline Pmin & 0 & 0 & 0 & 0 \\
\hline Qmax & 44.35 & 58.24 & 33.15 & 31.968 \\
\hline Qmin & -44.35 & -43.4 & -48.83 & -47.08 \\
\hline $\begin{array}{l}\text { MBASE } \\
\text { MVA) }\end{array}$ & 112 & 112 & 112 & 108 \\
\hline Zsource & $0.00932+$ & $0+\mathrm{j} 0.8$ & $0+\mathrm{j} 0.8$ & $0+\mathrm{j} 0.8$ \\
\hline Tx-MBASE & 125 & 125 & 125 & 125 \\
\hline $\begin{array}{l}\text { Tx- } \\
\text { Zsource } \%\end{array}$ & $0+\mathrm{j} 0.06$ & $0+\mathrm{j} 0.06$ & $0+\mathrm{j} 0.06$ & $0+\mathrm{j} 0.06$ \\
\hline
\end{tabular}

\begin{tabular}{|l|c|c|c|}
\hline \multirow{2}{*}{ TABLE II: GENERATOR DATA FOR THE STUDIED SYSTEM } \\
\cline { 2 - 4 } $\begin{array}{l}\text { Station } \\
\text { Name }\end{array}$ & \multicolumn{3}{|c|}{ Generator Information } \\
\hline HYDRO 1 & Hydro & 75 & No. of Machine \\
(MW) & 1 \\
\hline HYDRO 2 & Hydro & 360 & 1 \\
\hline GT 1 & Gas & 88 & 1 \\
\hline WF_MC & Wind farm & 100 & 67 \\
\hline
\end{tabular}

TABLE III: STUDIED FAULT INFORMATION

\begin{tabular}{|l|l|}
\multicolumn{1}{|c|}{ TABLE III: STUDIED FAULT INFORMATION } \\
\hline FRT 1 & Descriptions \\
\hline FRT 2 & Hard Fault at load bus 511 \\
\hline FRT 3 & $\begin{array}{l}\text { fault at 220 kV wind connection point for } 120 \mathrm{~ms} \text { and } \\
\text { cleared by tripping one line out of two. All farm output is } \\
\text { carrying by single line. Fault level is reduced } \\
\text { significantly }\end{array}$ \\
\hline
\end{tabular}

The transient stability for all wind turbines achieved within $15 \mathrm{sec}$ at $49.85 \mathrm{~Hz}$. The rate of change of frequency for GE and Furhlander wind turbines are faster than other three wind turbines, as shown in Fig. 7. The current contribution from all wind turbines are shown in Fig. 7, which are around 1.1 p.u.

Frequency disturbance 2 (FD2): a similar fault as FD1 with different value of inertia and machine MVA is introduced at Bus151 and the results are shown in Fig. 8. In this case, the system is slightly modified to make it weaker to observe the impact of large frequency excursion. The MVA of the machine at Bus 151 is changed from 1000 MVA to 150 MVA and inertia constant from $3.37 \mathrm{~s}$ to $10 \mathrm{~s}$. As a result, the system experienced severe frequency deviation than FD1. The largest frequency drop is $47.6 \mathrm{~Hz}$ for wind turbine without inertia whereas and the least frequency drop occurs for Furhlander to $48.7 \mathrm{~Hz}$. The transient stability for all wind turbines achieved within $30 \mathrm{sec}$ at $49.5 \mathrm{~Hz}$. Furhlander wind turbine shows faster rate of change of frequency with lowest frequency drop whereas the Generic model show the slowest rate of change of frequency than other models. The transient stability for all wind turbines achieved within 25 to $30 \mathrm{sec}$ except the Generic model which shows some oscillations before it settled at $60 \mathrm{sec}$. The Furhlender provides $1.28 \mathrm{pu}$ current during fault whereas others contribute below $1.1 \mathrm{pu}$.

Fig. 8(a) shows the comparison of frequency deviation of different wind turbine models for FD1 and FD2 disturbances ad Fig. 8(b) shows the comparison of rate of change off frequency of different wind turbine models for FD1 and FD2 disturbances.

B. Voltage Disturbances: Three different voltage disturbances are investigated. The details of faults are shown in Table III. The duration of faults is $120 \mathrm{~ms}$.

Fig.9 shows voltage disturbance FRT1 responses for different wind models. During the fault, terminal voltages drops to $0.15 \mathrm{pu}$ for Acciona and Furhlander, and 0.3 pu for GE and generic. As shown in Fig.9, the voltage recovery patterns after fault are different for different wind turbines. The voltage for connection point is settled within 10 cycles $(200 \mathrm{~ms})$ after the fault cleared.

Fig. 10 shows voltage disturbance FRT2 responses for different ind models. During the fault, terminal voltages drop to $0.5 \mathrm{pu}$ for Acciona, 0.6 for GE, Generic and Furhlander. As shown in Fig.11, the voltage recovery patterns after fault are different for different wind turbines. The voltage for connection point is settled within 10 cycles $(200 \mathrm{~ms})$ after the fault is cleared.

Fig. 11 shows voltage disturbances FRT3 responses for different wind models. During the fault, terminal voltages drops to $0.02 \mathrm{pu}$ for Acciona, 0.2 for GE, 0.3 for Generic and 0.0 pu for Furhlander. As shown in Fig.15, the voltage recovery patterns after fault are different for different wind turbines. The voltage for connection point is settled within 10 cycles $(200 \mathrm{~ms})$ after the fault cleared.

Most grid codes require wind farms to support grid voltage with additional reactive current during a voltage dip or increased reactive power consumption in the event of a voltage swell. The voltage control must be activated with first cycle of the fault. The wind turbine is required to start its active power recovery as soon as the voltage is at a required level after the fault clearance. The level of voltage varies according to the grid code requirements for the network. The rapid active power recovery process may cause voltage swings and instability. A slow recovery can minimise the possibility of instability. Most of the wind turbine model investigated are able to provide reactive current during fault for stabilizing the voltage as shown in Fig. 11 and Fig.15. 

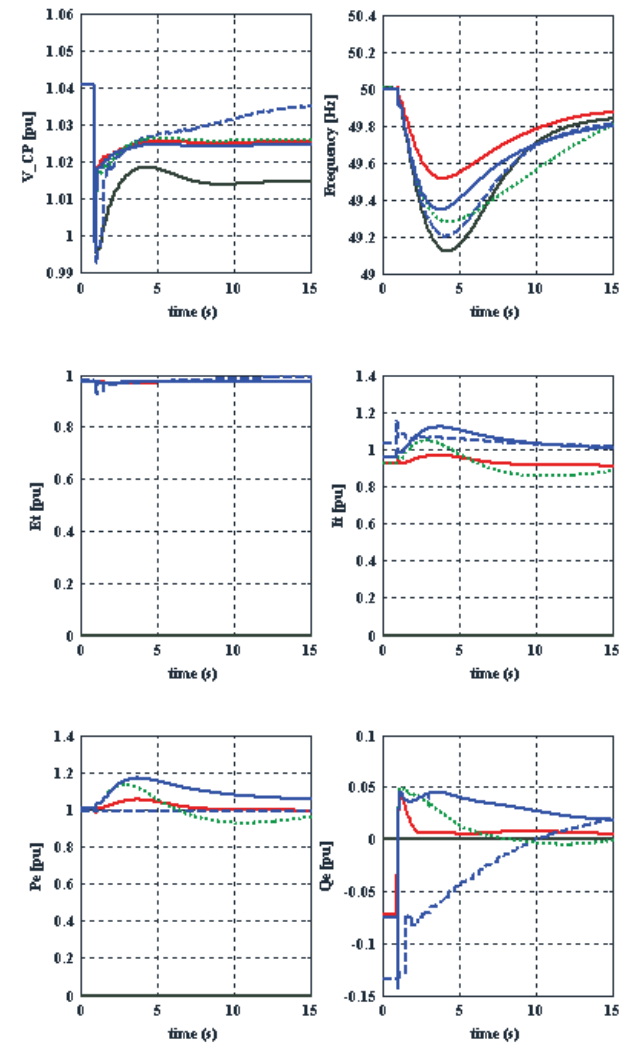

- No Getia - GE ------ Aciona $\cdots \cdots \cdots \cdots$ Geneic - FL

Fig. 6. System responses to frequency disturbance 1 (FD1) .
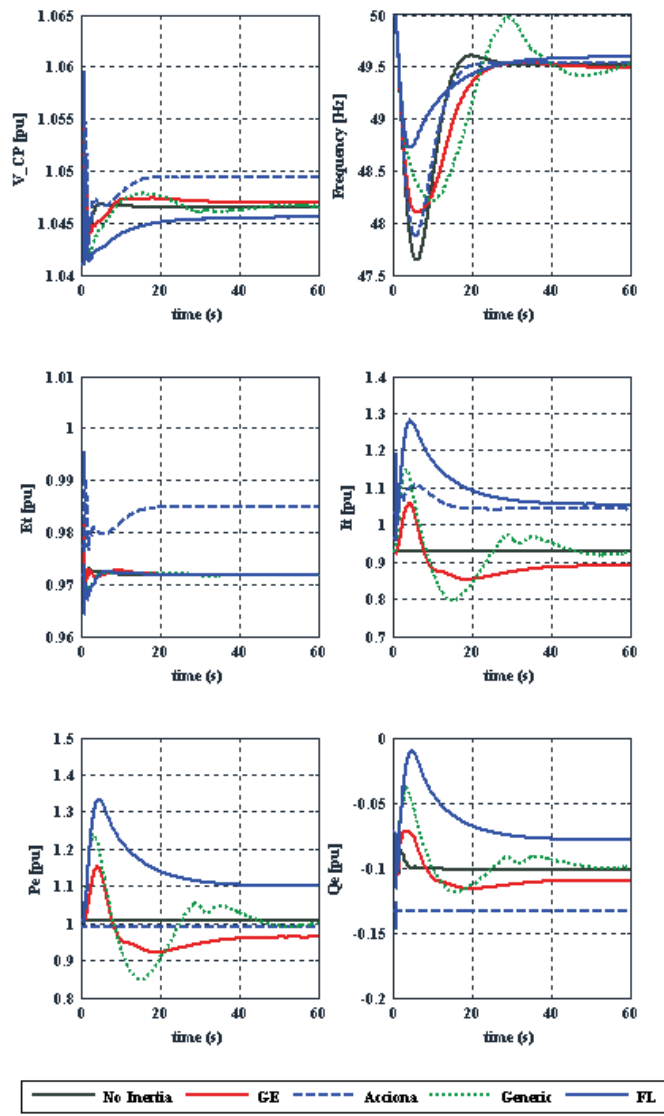

Fig. 7. System responses to frequency disturbance 2 (FD2)

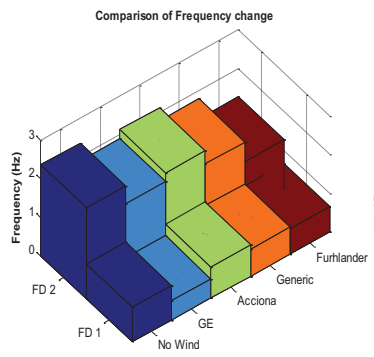

(a)

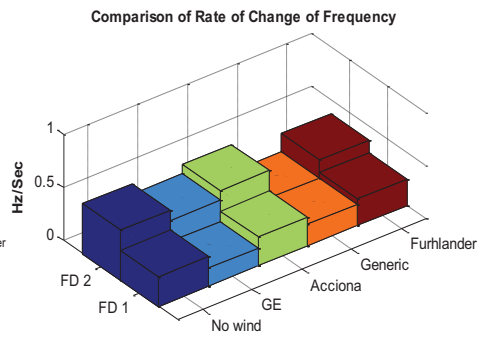

(b)
Fig. 8. (a) Comparison of frequency deviation of different wind turbine models for FD1 and FD2 disturbances. (b) Comparison of rate of change off frequency of different wind turbine models for FD1 and FD2 disturbances.

The possible cause of this may include model sensitivity to network disturbances or more rigid fault application procedure. For the sake of the simplicity, further investigations on these issues are not conducted in this work.

Fig.12 (a) shows the comparison of rate of change of active power of different wind turbine models for voltage disturbance FRT1, FRT2, and FRT3. This figure does not include Generic model as the rate of change of active power after fault cleared is zero. The rate of change of active power for acciona model occurs in two steps as shown in Fig.12 (a). Fig.12(b) shows the comparison of active power recovery time after fault clearance for different voltage disturbances..
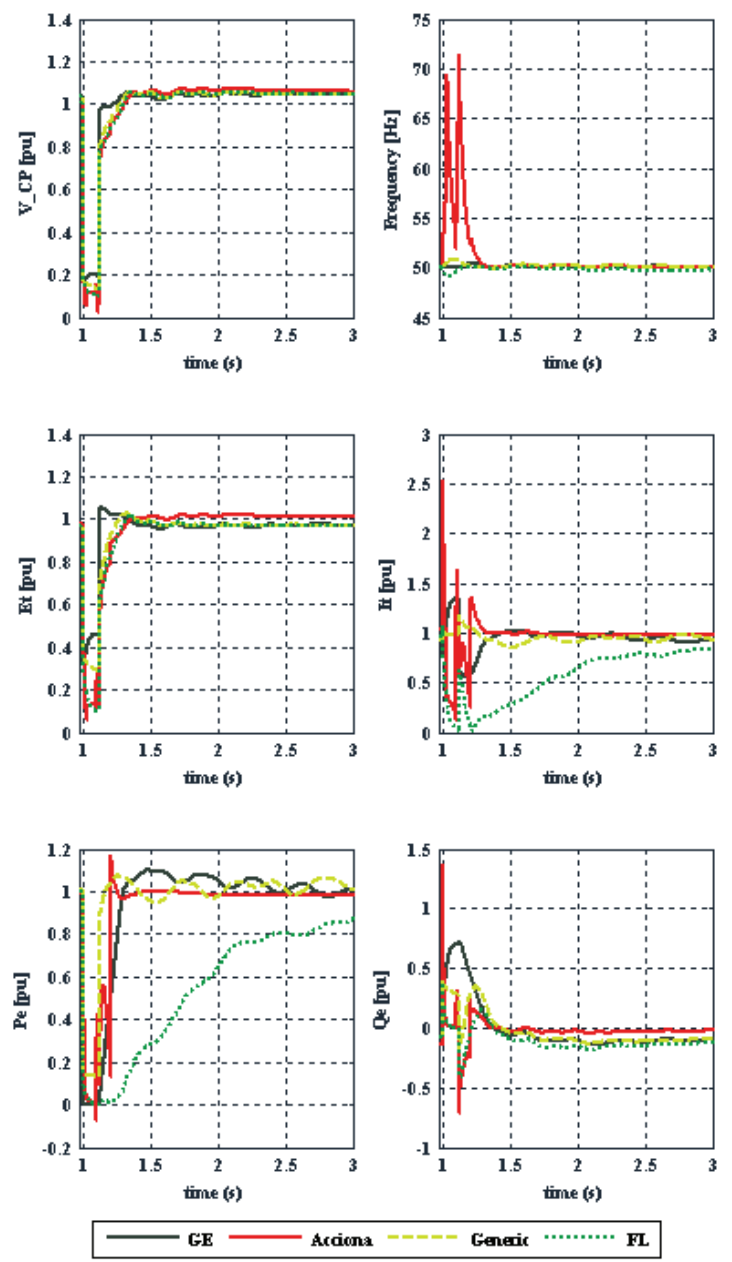

Fig. 9. System responses to FRT1 responses for different wind models. 

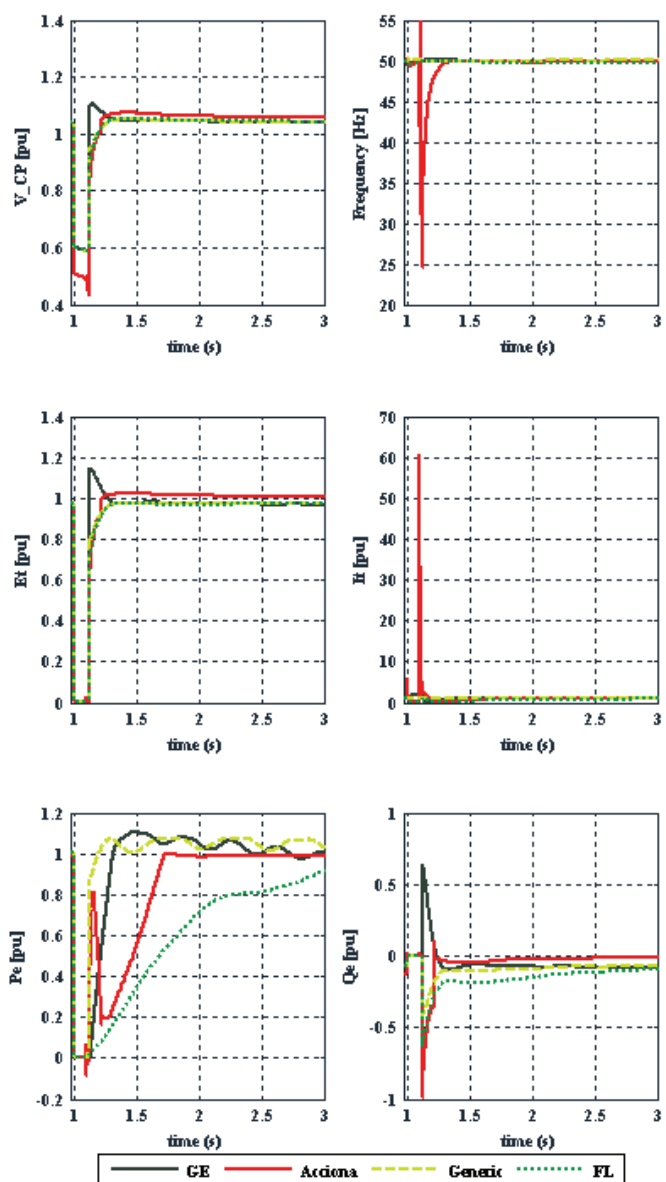

Fig. 10. System responses to FRT2 responses for different wind models.
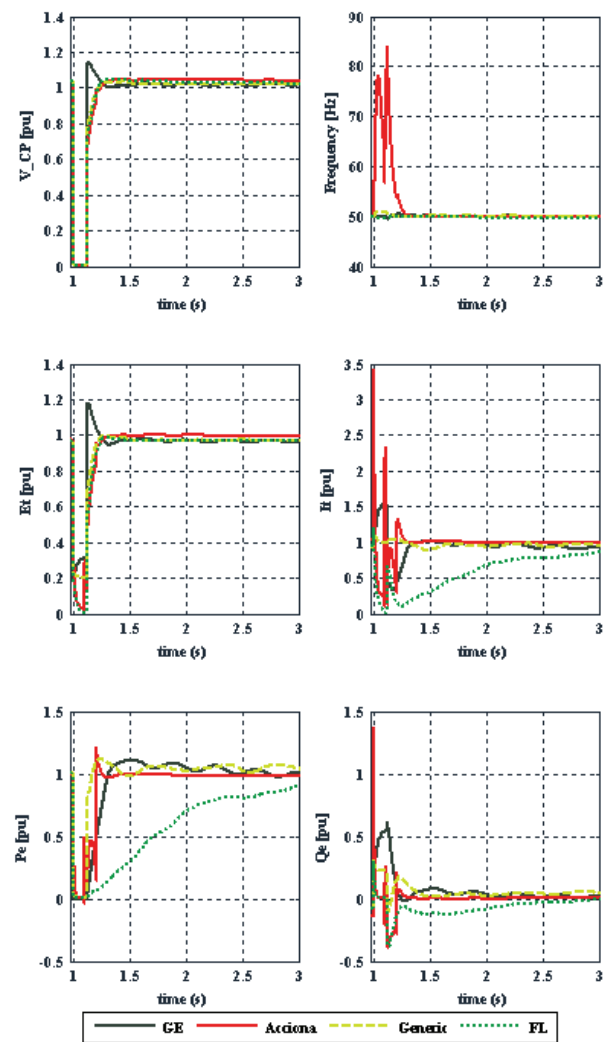

Fig. 11. System responses to FRT3 responses for different wind models.
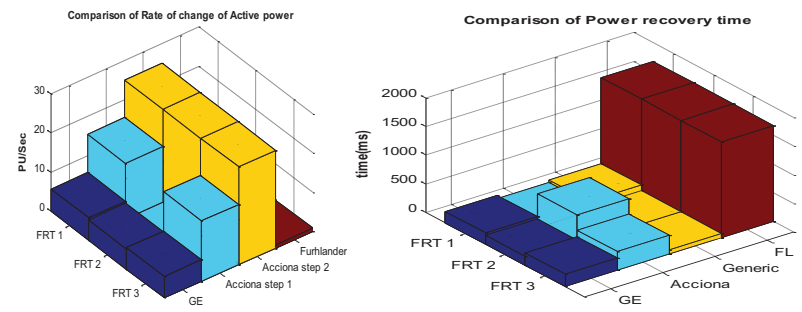

Fig. 12. (a) Comparison of rate of change of active power under voltage disturbances. (b) Comparison of power recovery time deviation under voltage disturbances.

\section{CONCLUSIONS}

Impacts of modern DFIG-bases wind turbines on voltage and frequency control have been investigated in this paper. Simulation studies have been carried out using PSSE on a real power system network with different energy sources which include DFIG based variable speed wind turbine, synchronous generator based hydro and gas power plants. Impact of modern commercially available DFIGbased wind turbines on system voltage and frequency control are investigated under different voltage and frequency contingencies and grid disturbances. The effect of inertia, loss of generations and loads on system frequency and effect of different faults on system voltage are investigated and results are presented. The assessments of some of grid code requirements are also examined. The fault ride through capability of different DFIG based wind turbines is examined. The simulation results are presented and analyzed in accordance with the grid code requirements and model limitations. Results show that DFIG-based wind turbines are capable to contribute on system frequency and voltage regulation under different contingencies. The comparative responses for four DFIG based wind turbines generators are analyzed. Results show that most of the wind turbines have the capability to contribute required reactive current during voltage contingencies.

\section{REFERENCES}

[1] F. M. Hughes, O. Anaya-Lara, N. Jenkins, and G. Strbac, "Control of DFIG based wind generation for power network support," IEEE Transactions on Power Systems, vol. 20, no. 4, pp. 1958-1966, Nov 2005.

[2] D. Gautam, L. Goel, R. Ayyanar, V. Vittal, and T. Harbour, "Control strategy to mitigate the impact of reduced inertia due to doubly fed induction generators on large power systems, "IEEE Transactions on Power Systems, vol 26, no. 1, pp. 214-224, Feb 2011.

[3] C. Rahmann, H. Haubrich, A. Moser, R. Palma-Behnke, L. Vargas, and M B. C. Salles, "Justified fault-ride-through requirements for wind turbines in power systems," IEEE Transactions on Power Systems, vol. 26, no. 3, pp. 1555-1563, Aug 2011.

[4] A. Miller, E. Muljadi, and D. S. Zinger, "A variable speed wind turbine power control," IEEE Transactions on Energy Conversion, vol. 12, no. 2, pp. 181-186, June 1997.

[5] L. Makhlouf and S. Lassaad, "Steady state analysis of a doubly-fed induction generator," in 2017 International Conference on Green Energy Conversion Systems (GECS), March 2017, pp. 1-6.

[6] R. Doherty, A. Mullane, G. Nolan, D. J. Burke, A. Bryson, and M O'Malley, "An assessment of the impact of wind generation on system requency control," IEEE Transactions on Power Systems, vol. 25, no. 1, pp. 452-460, Feb 2010.

[7] "Delivering energy and climate solutionsewea 2007 annual report, European wind energy association (ewea)," 2008.

[8] A. Mullane and M. O'Malley, "The inertial response of inductionmachinebased wind turbines," IEEE Transactions on Power Systems, vol. 20 no. 3, pp. 1496-1503, Aug 2005.

[9] J. Ekanayake and N. Jenkins, "Comparison of the response of doubly fed and fixed-speed induction generator wind turbines to changes in network frequency," IEEE Transactions on Energy Conversion, vol. 19, no. 4, pp. 800 802, Dec 2004

[10] G. M. Masters, Renewable and Efficient Electric Power Systems. New York: Willey and Sons, 2005.

[11] M. M. Chowdhury, M. E. Haque, S. Saha, M. A. Mahmud, A. Gargoom, and A. M. T. Oo, "An enhanced control scheme for an ipm synchronous generator based wind turbine with MTPA trajectory and maximum power extraction," IEEE Transactions on Energy Conversion, vol. 33, no. 2, pp.556566, June 2018. 